\title{
Foreign Direct Investment, Local Content Requirements and Regional Resource Allocation
}

\author{
SHIGEMI YABUUCH *
}

Nagoya City University

\begin{abstract}
This paper investigates the effects of foreign direct investment (FDI) into the export processing zones (EPZs) on factor rewards, national income, and the price and output of a domestic intermediate good producing sector (backward linkage effect) under a local content requirement (LCR) by the host government. FDI has important regional resource allocation effects between the domestic region and EPZ through the backward linkage effect. It also examines the effects of a change in the LCR itself on these variables.
\end{abstract}

\section{Introduction}

Both advanced and developing countries are interested in capital investment. Advanced countries invest their capital in developing countries to enjoy their low wage rates and to circumvent the protective barriers of the latter countries. On the other hand, developing countries want to attract foreign capital and advanced technology into their countries, especially into so-called export processing zones (EPZs) or duty free zones (DFZs), to stimulate domestic sectors through (inter-industry) linkage effects, to mitigate the balance of payments problem by increasing export earnings, and to alleviate the problem of unemployment. Various aspects of DFZs and EPZs have been discussed by several trade theorists such as Hamada (1974), Rodriguez (1976), Hamilton and Svensson (1982), Young (1987, 1992), Young and Miyagiwa (1987), Beladi and Marjit (1992), Miyagiwa (1993) and Yabuuchi (1997, 2000).

An ingenious model, which incorporates EPZs and an intermediate good-producing sector, was presented by Din (1994). He focussed his attention on the effects of EPZs in stimulating the domestic sectors through backward linkages. These linkages were established through the input-output relations between EPZs and domestic intermediate good-producing sectors. Din showed that if the intermediate good is internationally traded, then an increase in foreign capital investment in the EPZs (associated with the establishment of the EPZs or an increase in their activity) has no effect on

* I wish to thank to Professors Murray Kemp, Yoshio Kimura, Sumio Kakimoto, Nobuhiro Okuno, Ryuuhei Okumura, all participants of the seminar at Nagoya University, and two anonymous referees for the useful and constructive comments. 
factor rewards or, therefore, on national income, and it has a harmful (beneficial) effect on the intermediate good-producing activities if the intermediate good sector is labor (capital) intensive. These results are rather pessimistic in the light of the extensive use of foreign capital in developing countries because foreign investment is expected to increase domestic outputs, especially that of the intermediate good sector, through the backward linkage effect as well as to improve welfare. In order to fill the gap between the negative results obtained in the theoretical analysis and the real policy option employed in the real world, we introduce another important policy tool, that is, local content requirements (LCRs), and attempt to explain the implication of this policy mix for the performance of developing countries. Contrary to the Din's results, we will show that foreign investment may increase the output of the intermediate good sector, and it improves welfare.

Foreign firms in the EPZs prefer to import intermediate inputs from their home countries because of the price and/or quality considerations. On the other side, host countries hope to expand their own intermediate industries through the backward linkage effect, and they tend to impose the local content requirements (LCRs) on foreign firms. The policy requires that a certain percentage of domestic intermediate goods be used in the production of final products. As a general rule, WTO prohibits the use of LCRs, but exemptions apply to LDCs and/or new members for a certain period of time. Non-member countries, of course, seem to use the policy extensively as an effective policy to develop their domestic industries.

In Din's model, it is assumed that foreign firms rely entirely on intermediate inputs produced in the host countries. In the present paper, however, we introduce LCRs explicitly and focus our attention on the conflict of interest between the source and host countries. We investigate the effects of foreign direct investment (FDI) on the output and price of the intermediate good producing sector, factor rewards, and national income in the context of LCRs imposed by the host countries. We also examine the effects of changes in the LCRs on these variables.

Our main findings are as follows. An increase in FDI into the EPZs increases the output of the intermediate good sector under certain conditions. The change in the price of the intermediate good depends on the relative factor intensities of the domestic sectors. If the intermediate sector is labor intensive relative to capital compared with the other domestic sector, FDI causes the price to increase. On the other hand, if the intermediate sector is capital intensive, the price decreases. Therefore, the wage increases and the rental of domestic capital decreases according to the StolperSamuelson effect. Though the wage and rental rates change in opposite directions, we show that an increase in FDI unambiguously increases national income. The effects of a change in an LCR on backward linkages, factor rewards and national income are also examined. An increase in the LCR increases both the price and output of the intermediate good, as expected. Thus, the changes in factor rewards and national income depend on the factor intensities of the domestic sectors. An increase in the LCR may reduce the national income of the host country.

The rest of the paper is organized as follows. Section 2 presents the model and basic assump- 
tions. Section 3 examines the effects of FDI on the price and output of the intermediate good, factor rewards and national income under the LCR. Section 4 examines the effect of changes in the LCR on these variables. Finally, concluding remarks can be found in section 5 .

\section{The Model and Assumptions}

Let us consider a small open economy in which there are two zones: the domestic zone and the EPZ. The domestic zone produces two goods, $X_{1}$ and $X_{2}$, while the EPZ produces $X_{3}$. Production of $X_{1}$ requires labor $\left(L_{1}\right)$ and domestic capital $\left(K_{1}\right)$. Good 1 is a pure intermediate good, which is used in the production of goods 2 and 3. Sector 2 utilizes labor $\left(L_{2}\right)$, domestic capital $\left(K_{2}\right)$ and good 1 $\left(X_{12}\right)$, while sector 3 uses labor $\left(L_{3}\right)$, foreign capital $(V)$ and good $1\left(X_{13}\right)$. Thus, it is supposed that the intermediate good produced in sector 1 , for example, tires or the Brown tubes, is further processed into manufacturing product, automobiles or TV sets, respectively, in sectors 2 and 3 . The production functions are:

$$
\begin{aligned}
& X_{1}=F^{1}\left(L_{1}, K_{1}\right) \\
& X_{2}=F^{2}\left(L_{2}, K_{2}, X_{12}\right) \\
& X_{3}=F^{3}\left(L_{3}, V, X_{13}\right)
\end{aligned}
$$

$F^{j}$ is homogeneous of degree one in the inputs. Here, we suppose that the domestic sector 2 must use only the domestic intermediate input owing to the national policy, for example, a prohibitive tariff. On the other hand, the host government exempts foreign firms from the import tariff on the intermediate good. However, a certain proportion $(\alpha)$ of the total intermediate input used in the EPZ has to be bought in the local market. If the tax exemption is attractive enough compared with the cost of the LCR, foreign capital is induced into the EPZ. In the domestic intermediate good market, therefore, we have

$$
X_{1}=X_{12}+\alpha X_{13}
$$

Foreign firms imports the rest of the intermediate inputs $(1-\alpha) X_{13}$ from the home (or other) country at the constant world price $p_{1}{ }^{*}$. Thus, the effective input price of the intermediate good for the foreign firms is

$$
p_{1}^{e}=\alpha p_{1}+(1-\alpha) p_{1}^{*} .
$$

It is natural to suppose that the domestic intermediate industry is less efficient than the foreign counterpart. Thus, we assume that the domestic intermediate price, $p_{1}$, is higher than the foreign intermediate price, $p_{1}^{*}$, while both intermediate goods have the same quality.

Under competition, we have

$$
\begin{aligned}
& p_{1}=a_{L 1} w+a_{K 1} r \\
& p_{2}=a_{L 2} w+a_{K 2} r+a_{X 2} p_{1} \\
& p_{3}=a_{L 3} w+a_{V 3} s+a_{X 3} p_{1}^{e}
\end{aligned}
$$

where $a_{i j}$ is the amount of the $i$ th factor used in the $j$ th industry to produce one unit of the output, $w$ 
is wage rate, $r$ is rental of domestic capital, $s$ is rental of foreign capital, and $p_{j}$ is the price of the $j$ th $\operatorname{good}(j=1,2,3)$. We assume that goods 2 and 3 are tradable and then their prices are exogenously given. In addition, we suppose that $a_{X j}$ and $a_{V 3}$ are constant to focus our attention to the effects of the LCR, and to simplify the analysis. This is partly justified by the fact that four tires are used to produce a car and one Brown tube is used for a TV set.

Exogenously given endowments impose the resource constraints,

$$
\begin{aligned}
& a_{L 1} X_{1}+a_{L 2} X_{2}+a_{L 3} X_{3}=L \\
& a_{K 1} X_{1}+a_{K 2} X_{2}=K \\
& a_{V 3} X_{3}=V
\end{aligned}
$$

where $L$ and $K$ are the endowments of labor and capital, respectively. This completes the specification of our model with the fixed endowment of factors and the internationally determined prices. We have eight unknown variables, $w, r, s, X_{1}, X_{2}, X_{3}, p_{1}$ and $p_{1}^{e}$ which are solved by eight equations (4)-(11) for given parameters, $\alpha, p_{2}, p_{3}, L, K$ and $V$.

We do not specify the characteristic feature of consumption pattern of the host country, especially that of good 3 . It can be assumed that domestic consumers can buy good 3 as imports with and without a given tariff from the EPZ as well as the rest of the world.

\section{FDI and LCR}

\section{(3-1) Backward linkage effect}

We analyze the effects of FDI on factor prices and national income under the LCR. For this purpose, we will consider the exogenous increase in foreign capital investment $(V)$. Our analysis below crucially depends on the relative factor intensity of the three sectors. Since each sector employs a different set of inputs, it is useful to define the factor intensities clearly.

\section{Definition 1.}

Sector 1 is labor (capital) intensive relative to capital (labor) compared with sector 2 if and only if

$$
\begin{aligned}
L_{1} / K_{1}>(<) L_{2} / K_{2} & \Leftrightarrow \Lambda \equiv \lambda_{L 1} \lambda_{K 2}-\lambda_{L 2} \lambda_{K 1}>(<) 0 \\
& \Leftrightarrow \Theta \equiv \theta_{L 1} \theta_{K 2}-\theta_{L 2} \theta_{K 1}>(<) 0 .
\end{aligned}
$$

where $\lambda_{i j}$ is the allocative share of the $i$ th factor in the $j$ th industry (e.g., $\lambda_{K 2}=a_{K 2} X_{2} / K$ ), and $\theta_{i j}$ is the distributive share of the $i$ th factor in the jth industry (e.g., $\theta_{L 1}=w a_{L 1} / p_{1}$ ).

Though both cases of the factor intensity are possible, it is not unusual to suppose that sector 1 produces a simple intermediate good that is used to produce a more complicated final good in sector 2. Thus, the case where sector 1 is labor intensive relative to capital compared with sector 2 may be more relevant than the other case.

Definition 1 defines the factor intensity of domestic sectors in the physical sense. On the other hand, let us define the following factor intensities of the final good sectors of the economy. 


\section{Definition 2.}

Sector 3 is domestic intermediate good intensive relative to labor compared with sector 2 if and only if

$$
X_{12} / L_{2}<\alpha X_{13} / L_{3} \Leftrightarrow A \equiv \mu_{X 2} \lambda_{L 3}-\alpha \mu_{X 3} \lambda_{L 2}<0
$$

where $\mu_{X j}=X_{1 j} / X_{1}=a_{X j} X_{j} / X_{1}$.

Comparative statics yields the following result (see the Appendix A).

$$
\hat{X}_{1} / \hat{V}=\theta_{V 3}\left\{\theta_{K}\left(\mu_{X 2} \lambda_{L 3}-\alpha \mu_{X 3} \lambda_{L 2}\right) / \theta_{L}-\alpha \mu_{X 3} \lambda_{K 2}\right\} Q_{L L} / \Delta,
$$

where $\hat{z}=d z / z$ for any variable $z, \theta_{L}=w L / y, \theta_{K}=r K / y$,

$$
Q_{L L}=\sum_{j=1}^{2} \lambda_{L j} Q_{L L}^{j}=\sum_{j=1}^{2} \lambda_{L j}\left(w / a_{L j}\right)\left(\partial a_{L j} / \partial w\right)
$$

and $\Delta$ is the value of the determinant of the coefficient matrix of the system,

$$
\Delta=-\theta_{V 3}\left\{\left(\mu_{X 2} \lambda_{K 1}+\lambda_{K 2}\right) Q_{L L}+\left(\mu_{X 2} \lambda_{L 1}+\lambda_{L 2}\right) Q_{K K}\right\}>0 .
$$

Thus, the following proposition is immediate.

\section{Proposition 1.}

An increase in FDI increases the output of the intermediate good if and only if $\alpha>\theta_{K} \mu_{X 2} \lambda_{L 3} /$ $\mu_{X 3}\left\{\left(\theta_{K} \lambda_{L 2}+\theta_{L} \lambda_{K 2}\right)\right.$.

FDI increases the output of the foreign sector 3 , and attracts labor from the domestic sectors 1 and 2. Thus, if the intermediate good sector 1 is labor intensive relative to capital compared with sector 2, the output of sector 1 decreases through the Rybczynski effect, while the outputs of both sectors 2 and 3 increase. The increased demand for the intermediate good due to the expansion of sectors 2 and 3 may outweigh the initial decrease in the production of sector 1 . We can see from (12) that if $\alpha$ is larger than a certain value, then an increase in FDI expands the output of the intermediate good sector. This is because the expanding sector 3 uses relatively large amount of domestic intermediate good. This derived demand effect dominates the initial resource allocation effect, hence an increase in FDI has a positive backward linkage effect.

On the other hand, if the intermediate good sector is capital intensive relative to labor compared with sector 2 , the output of the intermediate good sector increases and that of sector 2 decreases through the Rybczynski effect. Therefore, the derived-demand effect is not certain and may be negative. Under the condition provided in Proposition 1, the direct resource allocation effect outweighs the derived demand effect, hence the output of the intermediate good increases even if the demand effect is negative. It is interpreted that large $\alpha$ contributes to increase or decrease less through the increase in the derived demand for the intermediate good. Thus, a restrictive LCR is likely to have a positive backward linkage effect.

If the foreign sector (sector 3 ) is intermediate good intensive relative to labor compared with the domestic sector (sector 2), i.e., $\mu_{X 2} \lambda_{L 3}>\mu_{X 3} \lambda_{L 2}$, then $\theta_{K} \mu_{X 2} \lambda_{L 3} / \mu_{X 3}\left\{\left(\theta_{K} \lambda_{L 2}+\theta_{L} \lambda_{K 2}\right)<1\right.$. Therefore, there exists such a level of LCR $(\alpha)$ as $0 \leq \alpha \leq 1$. On the contrary, if the domestic sector (sector 2) is 
strongly intermediate good intensive relative to labor compared with the foreign sector (sector 3), and $\theta_{K}$ is large relative to $\theta_{L}$, then $\alpha$ may not exist between zero and one.

Now let us examine the effect of the FDI on the price of the intermediate good. We have

$$
\hat{p}_{1} / \hat{V}=\theta_{V 3} \Pi \Theta / \Delta
$$

where

$$
\Pi=\alpha \mu_{x 3} \Lambda+\lambda_{L 3}\left(\lambda_{K 1} \mu_{X 2}+\lambda_{K 2}\right) .
$$

Thus, if the intermediate good sector is labor intensive relative to capital compared with sector 2 , it can be seen that $\Pi>0$ since $\Lambda>0$. On the other hand, $\Pi$ can be rewritten as

$$
\Pi=\lambda_{K 1} A+\lambda_{K 2}\left(\alpha \mu_{X 3} \lambda_{L 1}+\lambda_{L 3}\right)>0 .
$$

This shows that even if the intermediate good sector is capital intensive relative to labor compared with sector 2 (i.e., $\Lambda<0$ ), $\Pi$ is positive if sector 2 is domestic intermediate good intensive relative to sector 3 (i.e., $A>0$ ).

Here, let us define the aggregate capital-labor ratios in sectors 2 and 3 as

$$
\tilde{k}_{2}=\left(a_{K 2}+a_{K 1} a_{X 2}\right) /\left(a_{L 2}+a_{L 1} a_{X 2}\right)
$$

and

$$
\tilde{k}_{3}=\alpha a_{K 1} a_{X 3} /\left(a_{L 3}+\alpha a_{L 1} a_{X 3}\right),
$$

respectively, where $a_{K 2}+a_{K 1} a_{X 2}$ is the amount of capital used in sector 2 directly $\left(a_{K 2}\right)$ plus indirectly through the intermediate input $\left(a_{K 1} a_{X 2}\right)$ to produce one unit of the output, and so on. Thus, the pure intermediate sector 1 is integrated into the other two sectors 2 and 3 , hence the economy has two hypothetical aggregate sectors. Since sector 3 does not use the domestic capital directly, it is natural that we make the following assumption about the factor intensities of the aggregate sectors.

\section{Assumption 1.}

The aggregate sector 2 is capital intensive relative to labor compared with the aggregate sector 3 (i.e., $\tilde{k}_{2}>\tilde{k}_{3}$ ).

We can show that $\tilde{k}_{2}>\widetilde{k}_{3}$ is equivalent to $\Pi>0$ (see the Appendix B). From the discussion above, therefore, we have the following remark on the relation between the direct and aggregate factor intensities.

\section{Remark 1.}

The aggregate sector 2 is capital intensive relative to labor compared with the aggregate sector 3 (i.e., $\Pi>0$ ) if either

(i) the domestic manufacturing sector (sector 2) is capital intensive relative to labor compared with the intermediate good sector (sector 1) (i.e., $\Lambda>0$ ),

or

(ii) sector 2 is domestic intermediate good intensive relative to labor compared with sector 3 , (i.e., $A>0$ ). 
It can be seen from the remark and the definition of $\Pi$ that if $\Lambda<0$, and $\alpha$ is large enough, i.e., $\alpha>\lambda_{L 3}\left(\lambda_{K 1} \mu_{X 2}+\lambda_{K 2}\right) /\left(-\mu_{X 3} \Lambda\right)$, then it holds that $\Pi<0$, or equivalently, $\tilde{k}_{2}<\widetilde{k}_{3}$.

Now let us go back to the effect on the price of the intermediate good. From (13), the result can be summarized as follows.

\section{Proposition 2.}

Under the Assumption 1 (i.e., $\Pi>0$ ), an increase in FDI increases (decreases) the price of the intermediate good if the intermediate good is labor (capital) intensive relative to capital compared with sector 2 .

The change in the intermediate good price depends on factor intensities. If the intermediate good sector is labor intensive relative to labor compared with sector 2 , an increase in foreign capital investment decreases the output of the intermediate good through the Rybczynski effect and increases the demand for the good through the backward linkage effect. Both of these effects create excess demand for the intermediate good, hence they increase its price.

If the intermediate good sector is capital intensive relative to labor compared with sector 2, the output of the intermediate good increases due to the increase in FDI, but the change in the demand for the good is not certain. The price will decrease if sector 2 is domestic intermediate good intensive relative to labor compared with sector 3 (i.e., $A>0$ ). In this case, the output of the foreign sector 3 increases and that of sector 2 decreases. Under the stated condition, therefore, the increase in the demand for the intermediate good is small or even negative. As a result, there will be an excess supply of the intermediate good, and hence the price will decrease.

\section{(3-2) Income distribution}

Consider now the effect of FDI on income distribution. The changes in factor rewards due to an increase in foreign capital investment into the EPZ are derived as follows.

$$
\begin{aligned}
& \hat{w} / \hat{V}=\theta_{V 3} \widetilde{\theta}_{K 2} \Pi / \Delta \\
& \hat{r} / \hat{V}=-\theta_{V 3} \widetilde{\theta}_{L 2} \Pi / \Delta,
\end{aligned}
$$

where $\widetilde{\theta}_{K 2}=\left(\theta_{K 1} \theta_{X 2}+\theta_{K 2}\right)$ and $\widetilde{\theta}_{L 2}=\left(\theta_{L 1} \theta_{X 2}+\theta_{L 2}\right)$. Thus we have the following proposition from (14).

\section{Proposition 3.}

Under the Assumption 1 (i.e., $\Pi>0$ ), an increase in FDI raises the wage and lowers the rental of domestic capital.

The effects of FDI on factor prices follow both the change in the price of the intermediate good and the Stolper-Samuelson theorem. That is, if the intermediate good sector is labor (capital) intensive relative to capital (labor) compared with sector 2, the increase (decrease) in the price of the intermediate good increases the wage which is the reward of the factor used intensively in the intermediate good sector (sector 1), and decreases the rental which is the reward of the other factor. 
It is also important to analyze the effect of FDI on national income. National income of the host country $(y)$ is given by

$$
y=w L+r K \text {. }
$$

Thus, the change in national income is expressed as

$$
\hat{y}=\theta_{L} \hat{w}+\theta_{K} \hat{r}
$$

Substituting (14) into (16), we have (see the Appendix C)

$$
\begin{aligned}
\hat{y} / \hat{V} & =\left\{\theta_{V 3}\left(\theta_{L} \tilde{\theta}_{K 2}-\theta_{K} \widetilde{\theta}_{L 2}\right)\right\} \Pi / \Delta \\
& =\theta_{V 3} w r L K \Pi^{2} / p_{2} y X_{2} \Delta .
\end{aligned}
$$

Thus, the following proposition highlights the result.

\section{Proposition 4.}

An increase in FDI increases national income.

It is noteworthy to point out that the effect of FDI on national income is unambiguous, while the change in factor rewards depends on the aggregate factor intensities. Let us first consider the case where foreign sector 3 is labor intensive relative to capital compared with domestic sector 2 in terms of the aggregate factor intensity (i.e., $\Pi>0$ ). FDI increases demand for labor, hence it raises the wage, while it lowers the rental of domestic capital in this case.

On the other side, FDI expands the production of sector 3 and contracts that of sector 2 (see the Appendix D). Thus, FDI increases the wage rate of labor that is used intensively in the expanding sector, and it decreases the rental of domestic capital that is used intensively in the contracting sector. Furthermore, we can see that $\theta_{L} / \theta_{K}>\widetilde{\theta}_{K 2} / \widetilde{\theta}_{L 2}$, that is, the share of labor income relative to that of domestic capital income in the economy as a whole is larger than the share in the aggregate sector 2. In this case, therefore, the contribution of the increase in the wage rate to national income is larger than the negative effect of the decrease in the rental of domestic capital. Thus, FDI leads to increase national income (see the Appendix C).

The reverse case where foreign sector 3 is capital intensive relative to labor compared with domestic sector 2 in terms of the aggregate factor intensity (i.e., $\Pi<0$ ) can be interpreted similarly.

The results on the effects of FDI are summarized in Table 1. Most results depend on the capitallabor intensity ranking between sectors 1 and 2, except for the result on the intermediate output.

Table 1. The effects of FDI

\begin{tabular}{|c|c|c|c|c|c|}
\hline & $X_{1}$ & $p_{1}$ & $w$ & $r$ & $y$ \\
\hline$\Lambda>0$ & $*$ & - & + & - & + \\
\hline$\Lambda<0$ & $*$ & + & + & - & + \\
\hline
\end{tabular}

In the table, asterisks $\left(^{*}\right)$ show that the effects depend on the value of the ratio of the domestic intermediate good to the total intermediate good $(\alpha)$ as shown in Proposition 1. 


\section{Changes in LCR}

Now we consider the effects of a change in the LCR itself on backward linkages, income distribution and national income.

\section{(4-1) Backward linkages}

Comparative statics yields the following results.

$$
\begin{aligned}
& \hat{X}_{1} / \hat{\alpha}=-\alpha \theta_{V 3} \mu_{X 3}\left(\lambda_{K 2} Q_{L L}+\lambda_{L 2} Q_{K K}\right) / \Delta>0 \\
& \hat{p}_{1} / \hat{\alpha}=\alpha \theta_{V 3} \mu_{X 3} \Lambda \Theta / \Delta>0
\end{aligned}
$$

Thus the following proposition is immediate.

\section{Proposition 5.}

An increase in LCR increases the output and price of the intermediate good.

If the host government enforces the LCR on foreign firms, they must replace some of the imports of the intermediate goods by domestic production. This increases demand for the domestic intermediate good, hence its output and price increase. Thus the host government succeeds in attaining its initial purpose. On the other hand, however, the enforcement of the LCR decreases the output of sector 2 since the expansion of the intermediate good sector attracts both labor and capital from sector 2 .

\section{(4-2) Income distribution}

Let us now examine the effects of the LCR on factor rewards and national income. We can obtain

$$
\begin{aligned}
& \hat{w} / \hat{\alpha}=\alpha \theta_{V 3} \mu_{x 3} \widetilde{\theta}_{K 2} \Lambda / \Delta>0 \\
& \hat{r} / \hat{\alpha}=-\alpha \theta_{V 3} \mu_{x 3} \widetilde{\theta}_{L 2} \Lambda / \Delta<0 .
\end{aligned}
$$

Therefore, the following proposition summarizes the results.

\section{Proposition 6.}

An increase in LCR increases (decreases) the wage and decreases (increases) the rental of domestic capital if the intermediate good sector 1 is labor (capital) intensive relative to capital (labor) compared with sector 2 (i.e., $\Lambda>(<) 0)$.

We showed in the previous section that the increasing LCR increases the price of the intermediate good. Thus, the results of Proposition 6 are straightforward from the Stolper-Samuelson theorem.

Finally, the effect of the increase in the LCR on national income is obtained as follows.

$$
\begin{aligned}
\hat{y} / \hat{\alpha} & =\alpha \theta_{V 3} \mu_{x 3}\left(\theta_{L} \widetilde{\theta}_{K 2}-\theta_{K} \widetilde{\theta}_{L 2}\right) \Lambda / \Delta \\
& =\alpha \theta_{V 3} \mu_{x 3} w r L K \Pi \Lambda / p^{2} y X_{2} \Delta .
\end{aligned}
$$


From (22), we obtain the following proposition.

\section{Proposition 7.}

Under the Assumption 1 (i.e., $\Pi>0$ ), an increase in LCR increases (decreases) national income if and only if $\Lambda>(<) 0$.

As shown above, the LCR expands the production of sector 1 (proposition 5). We can show that it contracts the production of sector 2 (see the Appendix E). It also can be seen from (11) that the foreign output is constant because FDI is fixed in the present case.

The change in factor rewards depends on the factor intensities of the domestic sectors (Proposition 6). If the intermediate good sector is labor intensive relative to capital compared with sector 2 (i.e., $\Lambda>0$ ), the LCR increases the wage rate of labor that is used intensively in the expanding sector 1 , and it decreases the rental of domestic capital that is used intensively in the contracting sector 1. Under the Assumption 1 (i.e., $\Pi>0$ ), the increase in the wage rate contributes to national income much larger than the decrease in the domestic rental as discussed in the Proposition 4 and the Appendix C. Thus, the increasing LCR leads to increase national income. Conversely, if the intermediate good sector 1 is capital intensive relative to labor compared with sector 2 (i.e., $\Lambda<0$ ), the results will be reversed.

The results obtained in this section are summarized in Table 2. It shows clearly that the effects of LCR depend on the capital-labor intensity ranking between sectors 1 and 2 .

Table 2. The effects of LCR

\begin{tabular}{|c|c|c|c|c|c|}
\hline & $X_{1}$ & $p_{1}$ & $w$ & $r$ & $y$ \\
\hline$\Lambda>0$ & + & + & - & + & + \\
\hline$\Lambda<0$ & + & + & + & - & - \\
\hline
\end{tabular}

\section{Concluding Remarks}

In this paper, we have studied the effects of FDI on the output and price of the intermediate good, factor rewards and national income under the LCR. If the intermediate good is internationally traded, under perfect competition, an increase in FDI in the EPZ increases that output of the good if the intermediate good sector is capital intensive. Under the LCR, however, the output of the intermediate good increases even if the intermediate good sector is labor intensive relative to sector 2 . It is also interesting that an increase in FDI raises the wage and lowers the rental of domestic capital under the LCR, while it has no effects on factor rewards, and then on national income, in the absence of the LCR. In the presence of LCR, however, it is shown that the increase in FDI increases national income. Therefore, FDI has more favorable effects under LCR than those without LCR. 
This explains the extensive use of FDI coupled with the LCR in many developing countries.

The effects of a change in the LCR on those variables are also examined. As the host government expects, an increase in LCR increases the output of the intermediate good. At the same time, however, the output of the other domestic sector decreases, one of the factor rewards decreases and national income may decrease due to the increasing LCR. Thus, the government of the host country faces both the positive effect of backward linkage and the possibly negative effects of resource allocation, income distribution and national income.

As an important policy implication, the imposition of the LCR succeeds to expand the domestic intermediate sector at the risk of national income if the intermediate good sector is capital intensive relative to labor compared with the domestic final good sector. Otherwise, the LCR is useful as a policy to expand the domestic intermediate sector as well as to increase national income. Though the factor intensity is a matter of empirical import, it is more relevant to suppose that intermediate good sector (sector 1) is likely to be labor intensive relative to capital compared with the domestic final good sector (sector 2). Our analysis provides one of the theoretical backgrounds for the extensive use of the LCR policy especially in developing countries.

\section{Appendix}

\section{[A] Comparative statics}

In this appendix, we derive some mathematical expressions employed in the text. Differentiating (4)-(11) and eliminating $p_{1}^{e}$, we obtain

$$
\left[\begin{array}{ccccccc}
\theta_{L 1} & \theta_{K 1} & 0 & -1 & 0 & 0 & 0 \\
\theta_{L 2} & \theta_{K 2} & 0 & \theta_{X 2} & 0 & 0 & 0 \\
\theta_{L 3} & 0 & \theta_{V 3} & \theta_{X 3} \theta_{p} & 0 & 0 & 0 \\
Q_{L L} & Q_{L K} & 0 & 0 & \lambda_{L 1} & \lambda_{L 2} & \lambda_{L 3} \\
Q_{K L} & Q_{K K} & 0 & 0 & \lambda_{K 1} & \lambda_{K 2} & 0 \\
0 & 0 & 0 & 0 & 0 & 0 & 1 \\
0 & 0 & 0 & 0 & -1 & \mu_{X 2} & \alpha \mu_{X 3}
\end{array}\right]\left[\begin{array}{c}
\hat{w} \\
\hat{r} \\
\hat{s} \\
\hat{p}_{1} \\
\hat{X}_{1} \\
\hat{X}_{2} \\
\hat{X}_{3}
\end{array}\right]=\left[\begin{array}{c}
0 \\
0 \\
\theta_{X 3} \theta_{p}^{*} \hat{\alpha} \\
0 \\
0 \\
\hat{V} \\
-\alpha \mu_{X 3} \hat{\alpha}
\end{array}\right]
$$

where $\theta_{p}=\alpha p_{1} / p_{1}^{e}, \theta_{p}^{*}=\alpha\left(p_{1}-p_{1}^{*}\right) / p_{1}^{e}$,

$$
\begin{aligned}
& Q_{L L}=\sum_{j=1}^{2} \lambda_{L j} Q_{L L}^{j}=\sum_{j=1}^{2} \lambda_{L j}\left(w / a_{L j}\right)\left(\partial a_{L j} / \partial w\right), \\
& Q_{K K}=\sum_{j=1}^{2} \lambda_{K j} Q_{K K}^{j}=\sum_{j=1}^{2} \lambda_{K j}\left(r / a_{K j}\right)\left(\partial a_{K j} / \partial r\right), \\
& Q_{L K}=\sum_{j=1}^{2} \lambda_{L j} Q_{L K}^{j}=\sum_{j=1}^{2} \lambda_{L j}\left(r / a_{L j}\right)\left(\partial a_{L j} / \partial r\right),
\end{aligned}
$$

and

$$
Q_{K L}=\sum_{j=1}^{2} \lambda_{K j} Q_{K L}^{j}=\sum_{j=1}^{2} \lambda_{K j}\left(w / a_{K j}\right)\left(\partial a_{K j} / \partial w\right)
$$


Solving (A1) for $\hat{X}_{1}$ with respect to $\hat{V}$, we have (12) in the text. Other expressions are derived similarly.

\section{[B] The equivalence of $\tilde{k}_{2}>\widetilde{k}_{3}$ and $\Pi>0$}

By definitions, we can show that

$$
\begin{aligned}
\tilde{k}_{2}-\tilde{k}_{3}= & \left(a_{K 2}+a_{K 1} a_{X 2}\right) /\left(a_{L 2}+a_{L 1} a_{X 2}\right)-\alpha a_{K 1} a_{X 3} /\left(a_{L 2}+a_{L 1} a_{X 2}\right) \\
= & \left\{a_{K 1}\left(a_{X 2} a_{L 3}-\alpha a_{X 3} a_{L 2}\right)+a_{K 2}\left(\alpha a_{X 3} a_{L 1}+a_{L 3}\right)\right\} /\left(a_{L 2}+a_{L 1} a_{X 2}\right)\left(a_{L 2}+a_{L 1} a_{X 2}\right) \\
= & \left(K L / X_{2} X_{3}\right)\left\{\lambda_{K 1}\left(\mu_{X 2} \lambda_{L 3}-\alpha \mu_{X 3} \lambda_{L 2}\right)+\lambda_{K 2}\left(\alpha \mu_{X 3} \lambda_{L 1}+\lambda_{L 3}\right)\right\} / \\
& \quad\left(L^{2} / X_{2} X_{3}\right)\left(\lambda_{L 2}+\lambda_{L 1} \mu_{X 2}\right)\left(\lambda_{L 2}+\lambda_{L 1} \mu_{X 2}\right) \\
= & (K / L) \Pi /\left(\lambda_{L 2}+\lambda_{L 1} \mu_{X 2}\right)\left(\lambda_{L 2}+\lambda_{L 1} \mu_{X 2}\right) .
\end{aligned}
$$

\section{[C] The derivation of (17)}

Here we derive (17) in the text, and examine the implication of the result. By definitions of $\theta_{L}, \theta_{K}$ and $\theta_{i j} \mathrm{~s}$, we have

$$
\begin{aligned}
\theta_{L} \widetilde{\theta}_{K 2}- & \theta_{K} \widetilde{\theta}_{L 2}=\theta_{L}\left(\theta_{K 1} \theta_{X 2}+\theta_{K 2}\right)-\theta_{K}\left(\theta_{L 1} \theta_{X 2}+\theta_{L 2}\right) \\
= & \left(w r K L / y p_{2} X_{2}\right)\left\{\left(\lambda_{K 1} \mu_{X 2}+\lambda_{K 2}\right)-\left(\lambda_{L 1} \mu_{X 2}+\lambda_{L 2}\right)\right\} \\
= & \left(w r K L / y p_{2} X_{2}\right)\left[\left(\lambda_{L 1}+\lambda_{L 2}+\lambda_{L 3}\right)\left(\lambda_{K 1} \mu_{X 2}+\lambda_{K 2}\right)\right. \\
& \left.-\left(\lambda_{K 1}+\lambda_{K 2}\right)\left\{\left(\lambda_{L 1}\left(1-\alpha \mu_{3}\right)+\lambda_{L 2}\right)\right\}\right] \\
= & \left(w r K L / y p_{2} X_{2}\right)\left[\lambda_{L 3}\left(\lambda_{K 1} \mu_{X 2}+\lambda_{K 2}\right)-\left(\lambda_{L 1}+\lambda_{L 2}\right)\left\{\lambda_{K 1}\left(1-\alpha \mu_{X 3}\right)+\lambda_{K 2}\right)\right. \\
& \left.-\left(\lambda_{K 1}+\lambda_{K 2}\right)\left\{\left(\lambda_{L 1}\left(1-\alpha \mu_{3}\right)+\lambda_{L 2}\right)\right\}\right] \\
= & \left(w r K L / y p_{2} X_{2}\right)\left[\lambda_{L 3}\left(\lambda_{K 1} \mu_{X 2}+\lambda_{K 2}\right)+\alpha \mu_{X 3}\left(\lambda_{L 1} \lambda_{K 2}-\lambda_{L 2} \lambda_{K 1}\right)\right] \\
= & \left(w r K L / y p_{2} X_{2}\right) \Pi,
\end{aligned}
$$

since $\lambda_{L 1}+\lambda_{L 2}+\lambda_{L 3}=1, \lambda_{K 1}+\lambda_{K 2}=1$ and $\mu_{X 2}+\alpha \mu_{X 3}=1$. From (A2), therefore, (17) in the text is immediate.

In the case where $\Pi>0$, (A2) implies that

$$
\theta_{L} / \theta_{K}>\widetilde{\theta}_{K 2} / \widetilde{\theta}_{L 2}
$$

or, equivalently,

$$
k=K / L<\tilde{k}_{2} \text {. }
$$

On the other hand, totally differentiating (6) and (7), we have

$$
\widetilde{\theta}_{L 2} \hat{w}+\widetilde{\theta}_{K 2} \hat{r}=\hat{p}_{2}=0
$$

Thus, we have from (A3) and (A4)

$$
\theta_{L} \hat{w}+\theta_{K} \hat{r}=\hat{y}>0 \text {. }
$$

\section{[D] The changes in $X_{2}$ and $X_{3}$ owing to FDI}

We can see easily from (11) that $\hat{X}_{3} / \hat{V}>0$. Furthermore, solving (A1) for $\hat{X}_{2}$ with respect to $\hat{V}$, we have

$$
\hat{X}_{2} / \hat{V}=\theta_{V 3}\left[\alpha \mu_{X 3} \lambda_{K 1} Q_{L L}+\left(\alpha \mu_{X 3} \lambda_{L 1}+\lambda_{L 3}\right) Q_{K K}\right] \Phi / \Delta
$$


where $\Phi=\left\{\left(\theta_{L 2}+\theta_{L 1} \theta_{X 2}\right)+\left(\theta_{K 2}+\theta_{K 1} \theta_{X 2}\right)\right\}$. This shows that $\hat{X}_{2} / \hat{V}<0$.

\section{[E] The changes in $X_{2}$ owing to LCR}

We obtain from (A1)

$$
\hat{X}_{2} / \hat{\alpha}=\theta_{V 3} \alpha \mu_{X 3}\left(\lambda_{K 1} Q_{L L}+\lambda_{L 1} Q_{K K}\right) \Phi / \Delta<0 .
$$

\section{References}

Beladi, H., and S. Marjit, 1992, Foreign capital and protectionism, Canadian Journal of Economics, vol. 25, 233-238.

Din, M. -u., 1994, Export processing zones and backward linkage, Journal of Development Economics, vol. 43, 369-385.

Hamada, K., 1974, An economic analysis of the duty free zone, Journal of International Economics, vol. 4, 225-241.

Hamilton, C., and L. O. Svensson, 1982, On the welfare effects of a 'duty free' zone, Journal of International Economics, vol. 13, 45-64.

Miyagiwa, K., 1993, The locational choice for free-trade zones: rural versus urban options, Journal of International Economics, vol. 40, 187-203.

Neary, J. P., 1981, On the Harris-Todaro model with intersectoral capital mobility, Economica, vol. 48, 219234.

Rodriguez, C. A., 1976, A note on the economics of the duty free zones, Journal of International Economics, vol. 6, 385-388.

Yabuuchi, S., 1997, Direct investment, monopoly and welfare, Pacific Economic Review, vol. 2, 135-141.

Yabuuchi, S., 2000, Export processing zones, backward linkages and variable returns to scale, Review of Development Economics, vol. 4, 268-278.

Young, L., 1987, Intermediate goods and the formation of duty-free zones, Journal of Development Economics, vol. 25, 369-384.

Young, L., 1992, Unemployment and the optimal export-processing zone, Journal of Development Economics, vol. 37, 369-385.

Young, L., and K. Miyagiwa, 1987, Unemployment and the formation of duty-free zones, Journal of Development Economics, vol. 26, 397-405. 